\title{
The role of prelimbic and anterior cingulate cortices in fear memory reconsolidation and persistence depends on the memory age
}

\author{
Thiago Rodrigues da Silva, Jeferson Machado Batista Sohn, Roberto Andreatini, \\ and Cristina Aparecida Stern
}

Department of Pharmacology, Federal University of Parana, Curitiba 81531-980, Brazil

\begin{abstract}
Reconsolidation is a time-limited process under which reactivated memory content can be modified. Works focused on studying reconsolidation mainly restrict intervention to the moments immediately after reactivation and to recently acquired memories. However, the brain areas activated during memory retrieval depend on when it was acquired, and it is relatively unknown how different brain sites contribute to reconsolidation and persistence of reactivated recent and remote fear memories. Here, we sought to investigate the participation of prelimbic (PL) and anterior cingulate cortices $(\mathrm{ACC})$ in recent $(1 \mathrm{~d}$ old $)$ and remote $(21 \mathrm{~d}$ old $)$ fear memory reconsolidation and persistence. Male Wistar rats were submitted to the contextual fear conditioning protocol. Tamoxifen (TMX), an estrogen receptor modulator known to inhibit protein kinase $C$ activity was used to interfere with these processes. When infused into the PL cortex, but not into the ACC, TMX administration immediately or $6 \mathrm{~h}$ after recent fear memory reactivation impaired memory reconsolidation and persistence, respectively. TMX administered immediately after remote memory reactivation impaired memory reconsolidation when infused into the PL cortex and ACC. However, remote memory persistence was only affected when TMX was infused $6 \mathrm{~h}$ after memory reactivation into the ACC and no effect was observed when TMX was infused $6 \mathrm{~h}$ after memory reactivation into PL cortex. Together, the findings provide further evidence on the participation of PL cortex and ACC in reconsolidation of recent and remote fear memories and suggest that the persistence of a reactivated fear memory becomes independent on the PL cortex with memory age and dependent on the ACC.
\end{abstract}

\begin{abstract}
Memory reconsolidation is a postretrieval/reactivation process suggested as the mechanism under which memories can be updated or changed (Sara 2010). After retrieval and reactivation, the consolidated memory trace is destabilized and reconsolidated thereafter, being susceptible to interventions during this period. Changes in memory reconsolidation are observed at short-term moments, such as $1 \mathrm{~d}$ after intervention and are long-lasting (Nader et al. 2000; Nader and Einarsson 2010; Alberini 2011; Stern et al. 2012). This feature may open an avenue for treating mental disorders, such as posttraumatic stress disorder (Gisquet-Verrier and Le Dorze 2019; Lisboa et al. 2019). The reconsolidation time window is suggested to last up to $6 \mathrm{~h}$ (Nader et al. 2000; Stern et al. 2012) however, most studies restrict the drug administration to moments immediately after reactivation of recent fear memories (Stern et al. 2012; Wan et al. 2014; Amiri et al. 2015; Murkar et al. 2019). Some authors have suggested that reactivation of a recent memory might contribute to memory persistence, a mechanism required to sustain long-term memories that involve late waves of protein synthesis (Nakayama et al. 2013, 2015; da Silva et al. 2016, 2020; Krawczyk et al. 2019). Behaviorally, amnesia induced by interferences in memory persistence is observed in a long-term manner, that is, $7 \mathrm{~d}$ after memory reactivation, and not in the short-term, such as $1 \mathrm{~d}$ later (Nakayama et al. 2015; da Silva et al. 2020). For instance, it has been found that inhibiting, PKC into the rats PL cortex for 6,9 , or $12 \mathrm{~h}$, the protein synthesis in the basolateral amygdala $9.5 \mathrm{~h}$, or ERK1/2 in the mice dorsal hippocampus $3 \mathrm{~h}$ af-
\end{abstract}

Corresponding author: cristina.stern@ufpr.br

Article is online at http://www.learnmem.org/cgi/doi/10.1101//m.051615.120. ter memory reactivation, respectively, impaired memory persistence without affecting the reconsolidation (Nakayama et al. 2013; Krawczyk et al. 2019; da Silva et al. 2020).

The brain areas activated during memory retrieval depend on when it was acquired. Evidence suggest that recent memories are more dependent on hippocampus activity to be retrieved than remote memories, which are dependent on cortical activity (Frankland et al. 2006; DeNardo et al. 2019; Makino et al. 2019), although there are studies showing that independent on the memory age, the hippocampus is also recruited (Makino et al. 2019). Similarly, it has been suggested that the reconsolidation of recent and remote fear memories relies on the hippocampus and cortical regions, respectively (Lee 2010; Einarsson and Nader 2012; Stern et al. 2014; Inaba et al. 2016; Vanvossen et al. 2017). More specifically, it has been shown that the reconsolidation of remote fear memories depends on the activity of the anterior cingulate (ACC) and prelimbic cortex (PL; Einarsson and Nader 2012; Stern et al. 2014), areas that integrate the medial prefrontal cortex (Vertes 2006) and that are directly or indirectly connected with the dorsal hippocampus (Debiec et al. 2002; Restivo et al. 2009; Goshen et al. 2011; Tayler et al. 2013; Aceti et al. 2015; Dolleman-van der Weel et al. 2019).

\footnotetext{
(C) 2020 da Silva et al. This article is distributed exclusively by Cold Spring Harbor Laboratory Press for the first 12 months after the full-issue publication date (see http://learnmem.cshlp.org/site/misc/terms.xhtml). After 12 months, it is available under a Creative Commons License (Attribution-NonCommercial 4.0 International), as described at http://creativecommons.org/licenses/by-nc/ $4.0 \%$.
} 
Tamoxifen (TMX) is an estrogen receptors modulator (Wang et al. 2002; Eigeliene et al. 2016) and inhibitor of protein kinase C (PKC) activity, both in rodents and humans (Abrial et al. 2013). Among the downstream-induced effects of PKC activation, the AMPA receptors trafficking and enhancement of BDNF (brainderived neurotrophic factor) expression are of relevance to sustaining long-term memory (Giese and Mizuno 2013). PKC activity in the PL cortex is necessary for both, reconsolidation and persistence of a reactivated fear memory (da Silva et al. 2020). Given systemically and immediately or $6 \mathrm{~h}$ after memory reactivation, TMX impaired the persistence of a contextual recent fear memory without affecting the reconsolidation (da Silva et al. 2016). However, it is unknown whether remote fear memory is susceptible to interferences in reactivated memory persistence and which brain areas are involved in reactivation-induced persistence of fear memory. Thus, we hypothesized that the reconsolidation and persistence of recent or remote reactivated fear memories would be differently coordinated by the PL cortex and ACC. Then, we evaluated the short- ( $1 \mathrm{~d}$ after) and long-term (7 d after) effects of TMX infused into the PL or ACC immediately or $6 \mathrm{~h}$ after recent or remote fear memory reactivation.

\section{Results}

\section{The effect of tamoxifen infused into the PL cortex immediately or $6 \mathrm{~h}$ after reactivation of recent fear memory}

Animals conditioned to Context A were randomly allocated in two groups and received vehicle or TMX $(0.25 \mu \mathrm{g} / 0.2 \mu \mathrm{L} / \mathrm{side})$ into the PL cortex immediately $(n=7-9)$ after memory reactivation. Repeated-measures ANOVA showed significant effect of Context A reexposures $\left[F_{(2,28)}=21.83 ; P=0.0001\right]$, treatment $\left[F_{(1,14)}=19.16 ; P=0.0006\right]$, and the interaction between Context A reexposures and treatment $\left[F_{(2,28)}=3.3752 ; P=0.04862\right]$. As shown in Figure $1 \mathrm{~B}$, all groups presented similar freezing time during memory reactivation. During Test $\mathrm{A}_{1}(P=0.001$; Hedges' $g$ effect size $g=2.745)$ and Test $\mathrm{A}_{2}(P=0.006$; Hedges' $g$ effect size $g$ $=1.481$ ), the Tukey post-hoc test showed significant difference between control and TMX-treated groups. The TMX-treated group presented less freezing time than controls and this effect lasted for at least $1 \mathrm{wk}$, suggesting an impairment in memory reconsolidation.

An independent group of conditioned animals was randomly allocated in two groups and received vehicle or TMX $(0.25 \mu \mathrm{g} / 0.2$ $\mu \mathrm{L} /$ side) into the PL $6 \mathrm{~h}(n=9-11)$ after memory reactivation. Repeated-measures ANOVA showed an effect of Context A reexposures $\left[F_{(2,36)}=24.58 ; P=0.00001\right]$, treatment $\left[F_{(1,18)}=21.40 ; P=\right.$ $0.0002]$, and the interaction between Context $\mathrm{A}$ reexposures and treatment $\left[F_{(2,36)}=10.62 ; P=0.0002\right]$. As shown in Figure $1 C$, there are no differences among groups during memory retrieval and Test $\mathrm{A}_{1}(P=0.11)$. However, during Test $\mathrm{A}_{2}(P=0.0001 ;$ Hedges' $\mathrm{g}$ effect size $g=3.224)$, the Tukey post-hoc test showed a significant difference between control and TMX-treated groups, suggesting an impairment in reactivated-memory persistence.

\section{The effect of tamoxifen infused into the ACC immediately or $6 \mathrm{~h}$ after reactivation of recent fear memory}

Animals conditioned to Context A were randomly allocated in two groups and received vehicle or TMX $(0.25 \mu \mathrm{g} / 0.2 \mu \mathrm{L} /$ side $)$ into the ACC immediately ( $n=8$ /group) after memory reactivation. Repeated-measures ANOVA showed a significant difference of Context-A reexposures $\left[F_{(2,28)}=36.30 ; P=0.00001\right]$, however, no significant difference of treatment $\left[F_{(1,14)}=0.09 ; P=0.75\right]$ or the interaction between Context $\mathrm{A}$ reexposures and treatment was observed $\left[F_{(2,28)}=0.15 ; P=0.85\right]$. As observed in Figure 2B, TMX-treated group present similar percentages of freezing time along the sessions, suggesting no effect in memory reconsolidation. There was a reduction of freezing time in Test $\mathrm{A}_{2}$ when compared with memory retrieval, suggesting an extinction of fear memory in both groups.

An independent group of conditioned animals was randomly allocated in two groups and received vehicle or TMX $(0.25 \mu \mathrm{g} / 0.2$ $\mu \mathrm{L} /$ side) into the ACC $6 \mathrm{~h}(n=7 /$ group $)$ after memory reactivation. Repeated-measures ANOVA showed a significant difference of Context A reexposures $\left[F_{(2,24)}=16.92 ; P=0.00003\right]$, however, no significant difference of treatment $\left[F_{(1,12)}=0.09 ; P=0.76\right]$ or the interaction between Context $\mathrm{A}$ reexposures and treatment was observed $\left[F_{(2,24)}=0.06 ; P=0.94\right]$. As observed in Figure 2C,

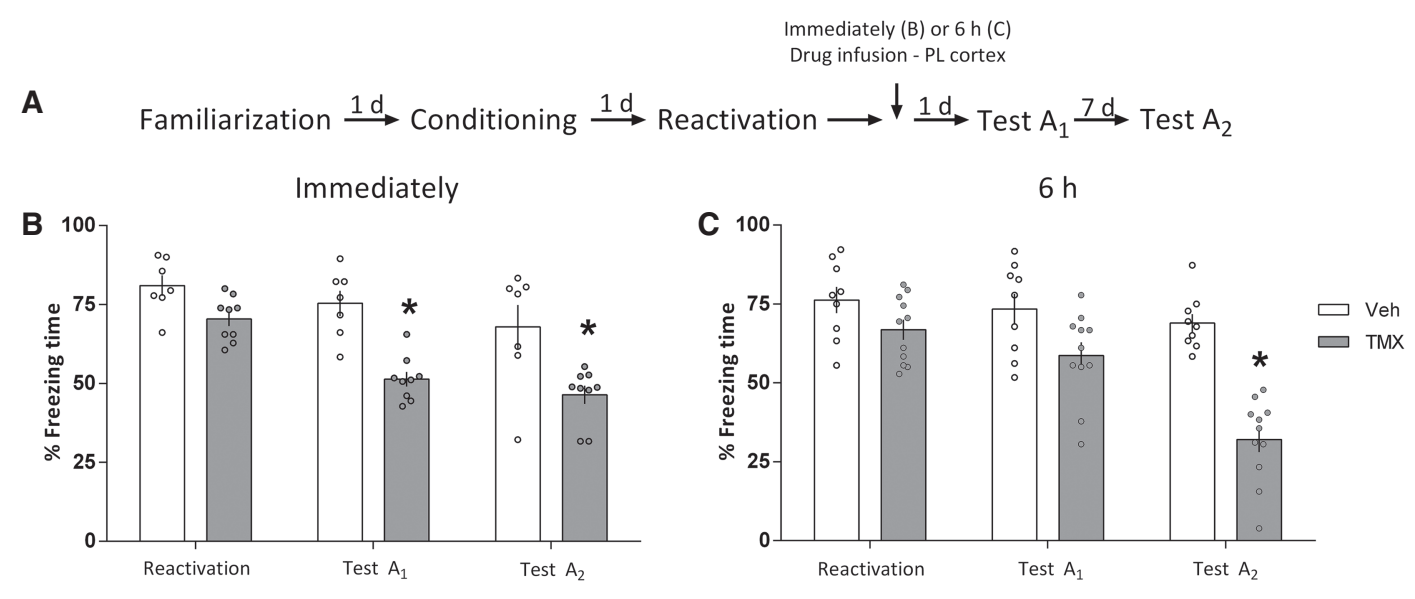

Figure 1. Recent fear memory reconsolidation and persistence relies on the PL cortex. $(A)$ The diagram represents the experimental design. Animals were familiarized to Context A, that was paired with three footshocks (US) a day later. After $24 \mathrm{~h}$, immediately or $6 \mathrm{~h}$ after recent memory reactivation, the animals received bilateral infusion of either vehicle (Veh) or TMX $(0.25 \mu \mathrm{g} / 0.2 \mu \mathrm{L})$ intra-PL cortex. One and seven days later, the animals were submitted to Tests $A_{1}$ and $A_{2}$ to assess TMX effects on memory. (B) Effects of TMX when given into PL cortex immediately after reactivation of recent fear memory. TMX-treated animals presented less freezing time than controls during Test $A_{1}$ and Test $A_{2}$, suggesting an impairment of recent memory reconsolidation. (C) Effects of TMX when given into PL cortex $6 \mathrm{~h}$ after reactivation of recent fear memory. TMX-treated animals presented less freezing time than controls only during Test $A_{2}$, suggesting an impairment of recent memory persistence. Values are expressed as mean \pm S.E.M. The asterisk indicates a statistically significant difference $(P \leq 0.05)$ from the respective control group. (Repeated-measures ANOVA followed by the Tukey test.) 


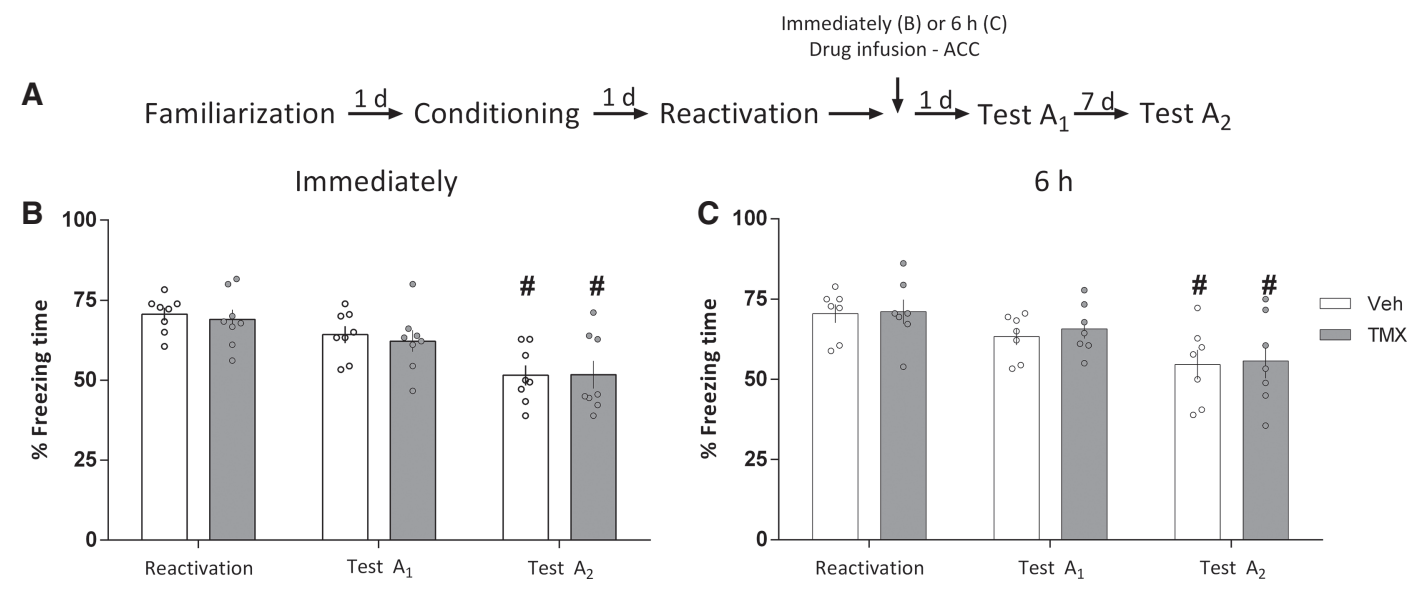

Figure 2. Recent fear memory reconsolidation and persistence do not rely on the ACC. $(A)$ The diagram represents the experimental design. Animals were familiarized to Context A, that was paired with three footshocks (US) a day later. After $24 \mathrm{~h}$, immediately or $6 \mathrm{~h}$ after recent memory reactivation, the animals received bilateral infusion of either vehicle (Veh) or TMX $(0.25 \mu \mathrm{g} / 0.2 \mu \mathrm{L})$ intra-ACC. One and seven days later, the animals were submitted to Tests $A_{1}$ and $A_{2}$ to assess TMX effects on memory. $(B)$ Effects of TMX when given into ACC cortex immediately after reactivation of recent fear memory. TMX-treated animals did not show significant differences in freezing behavior when compared to respective controls during Test $A_{1}$ and Test $A_{2}$. (C) Effects of TMX when given into ACC cortex $6 \mathrm{~h}$ after reactivation of recent fear memory. TMX-treated animals did not show significant differences in freezing behavior when compared to respective controls during Test $A_{1}$ and Test $A_{2}$. Values are expressed as mean \pm S.E.M. The hashtag indicates a statistically significant difference $(P \leq 0.05)$ from the reactivation session. (Repeated-measures ANOVA followed by the Tukey test.)

TMX-treated group present similar percentages of freezing time along the sessions, suggesting no effect in memory reconsolidation. There was a reduction of freezing time in Test $\mathrm{A}_{2}$ when compared with memory retrieval, suggesting an extinction of fear memory in both groups.

\section{The effect of tamoxifen infused into the PL cortex immediately or $6 \mathrm{~h}$ after reactivation of remote fear memory}

Animals conditioned to Context A were randomly allocated in two groups and received vehicle or TMX $(0.25 \mu \mathrm{g} / 0.2 \mu \mathrm{L} /$ side $)$ into the
PL cortex immediately ( $n=7-9)$ after remote memory reactivation, conducted $21 \mathrm{~d}$ after fear conditioning. Repeated-measures ANOVA showed significant effect of Context A reexposures $\left[F_{(2,28)}=29.14 ; P=0.00001\right]$, treatment $\left[F_{(1,14)}=15.15 ; P=0.001\right]$, and an interaction between Context A reexposures and treatment $\left[F_{(2,28)}=26.52 ; P=0.00001\right]$. As shown in Figure 3B, all groups presented similar levels of freezing during memory retrieval. During Test $\mathrm{A}_{1}(P=0.0007$; Hedges' $g$ effect size $g=5.046)$ and Test $\mathrm{A}_{2}(P=$ 0.0001; Hedges' $g$ effect size $g=2.099$ ), the Tukey post-hoc test showed significant difference between control and TMX-treated groups and this effect lasted for at least $1 \mathrm{wk}$, suggesting an impairment of remote memory reconsolidation.

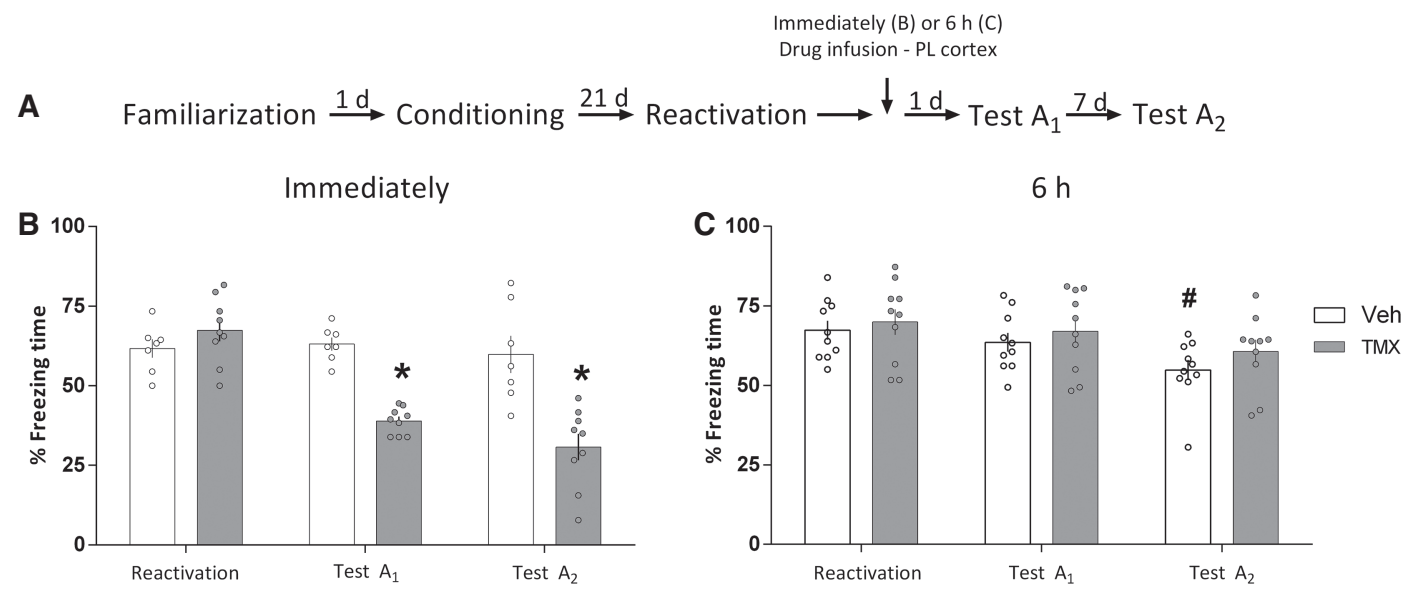

Figure 3. Remote fear memory reconsolidation relies on the PL cortex. $(A)$ The diagram represents the experimental design. Animals were familiarized to Context $A$, that was paired with three footshocks (US) a day later. After $21 \mathrm{~d}$, immediately or $6 \mathrm{~h}$ after remote memory reactivation, the animals received a bilateral infusion of either vehicle (Veh) or TMX $(0.25 \mu \mathrm{g} / 0.2 \mu \mathrm{L})$ intra-PL cortex. One and seven days later, the animals were submitted to Tests $\mathrm{A}_{1}$ and $\mathrm{A}_{2}$ to assess the TMX effects on memory. (B) Effects of TMX when given into PL cortex immediately after reactivation of remote fear memory. TMX-treated animals presented less freezing time than controls during Test $A_{1}$ and Test $A_{2}$, suggesting an impairment of remote memory reconsolidation. (C) Effects of TMX when given into PL cortex $6 \mathrm{~h}$ after reactivation of remote fear memory. TMX-treated animals did not show significant differences in freezing behavior when compared to respective controls during Test $A_{1}$ and Test $A_{2}$, suggesting that the persistence of a reactivated remote memory is independent of the PL cortex. Values are expressed as mean \pm S.E.M. The asterisk indicates a statistically significant difference $(P \leq 0.05)$ from the respective control group. The hashtag indicates a statistically significant difference $(P \leq 0.05)$ from Veh of Test $A_{2}$ compared to the memory reactivation section (Repeated-measures ANOVA followed by the Tukey test). 
An independent group of conditioned animals was randomly allocated in two groups and received vehicle or TMX $(0.25 \mu \mathrm{g} /$ $0.2 \mu \mathrm{L} /$ side) into the PL cortex $6 \mathrm{~h}(n=10 /$ group) after remote memory reactivation, conducted $21 \mathrm{~d}$ after fear conditioning. Repeated-measures ANOVA showed significant effect of Context-A reexposures $\left[F_{(2,36)}=24.50 ; P=0.0001\right]$, however, no significant difference of treatment $\left[F_{(1,18)}=0.73 ; P=0.40\right]$ or the interaction between Context-A reexposures and treatment was observed $\left[F_{(2,36)}=0.52 ; P=0.59\right]$. As observed in Figure $3 \mathrm{C}$ no change in freezing behavior was observed, suggesting that persistence of a reactivated remote memory is independent of the PL cortex.

\section{The effect of tamoxifen infused into the ACC cortex immediately or $6 \mathrm{~h}$ after reactivation of remote fear memory}

Animals conditioned to Context A were randomly allocated in two groups and received vehicle or TMX $(0.25 \mu \mathrm{g} / 0.2 \mu \mathrm{L} / \mathrm{side})$ into the ACC immediately $(n=7-8)$ after remote memory reactivation, conducted $21 \mathrm{~d}$ after fear conditioning. Repeatedmeasures ANOVA showed significant effect of Context A reexposures $\left[F_{(2,26)}=19.14 ; P=0.00001\right]$, treatment $\left[F_{(1,13)}=25.06 ; P=\right.$ $0.0002]$, and an interaction between Context $A$ reexposures and treatment $\left[F_{(2,26)}=3.4285 ; P=0.04770\right]$. As shown in Figure $4 \mathrm{~B}$, all groups presented similar levels of freezing during memory retrieval. During Test $\mathrm{A}_{1}(P=0.027$; Hedges' $g$ effect size $g=1.569)$ and Test $\mathrm{A}_{2}(P=0.001$; Hedges' $g$ effect size $g=2.213)$ the Tukey post-hoc test showed a significant difference between control and TMX-treated groups, suggesting an impairment of remote memory reconsolidation.

An independent group of conditioned animals was randomly allocated in two groups and received vehicle or TMX $(0.25 \mu \mathrm{g} / 0.2$ $\mu \mathrm{L} /$ side) into the PL $6 \mathrm{~h}(n=9 /$ group $)$ after remote memory reactivation, conducted $21 \mathrm{~d}$ after fear conditioning. Repeated-measures ANOVA showed significant effect of Context-A reexposures $\left[F_{(2,32)}\right.$ $=15.14 ; P=0.00002]$, treatment $\left[F_{(1,16)}=5.76 ; P=0.02\right]$, and the interaction between Context-A reexposures and treatment $\left[F_{(2,32)}=\right.$ $3.14 ; P=0.046]$. As observed in Figure $4 \mathrm{C}$ the TMX-treated group presented less fear behavior than control in Test $\mathrm{A}_{2}(P=0.02$;
Hedges' $^{\prime} g$ effect size $g=1.391$ ) suggesting that persistence of reactivated remote memory is dependent of the ACC.

\section{Discussion}

Our results showed that TMX administered into the PL cortex immediately after memory retrieval impaired the reconsolidation of recent and remote fear memory; the treatment with TMX into the PL cortex $6 \mathrm{~h}$ after memory reactivation impaired the persistence of the recent fear memory, but not the persistence of remote memory; the TMX infusion into the ACC immediately after memory retrieval impaired the reconsolidation of remote fear memory without affecting the recent memory; the treatment with TMX into the ACC $6 \mathrm{~h}$ after memory reactivation impaired the persistence of the remote fear memory, but not the persistence of the recent fear memory.

Rats that received TMX into the PL cortex immediately after memory reactivation presented less freezing behavior than controls on the following day, suggesting an impairment in fear memory reconsolidation. This result agrees with studies showing the participation of this area in reconsolidation of recent fear memories by inhibiting mTOR, blocking the $\mathrm{CB} 1$ or the alpha- 1 adrenergic receptors, by inactivating it with muscimol or activating it with DREADDs or with a NMDA receptor agonist (Do Monte et al. 2013; Stern et al. 2014, 2015; Levin et al. 2017; Vanvossen et al. 2017; Ye et al. 2017). Importantly, the TMX effect lasted for at least $1 \mathrm{wk}$, suggesting no spontaneous recovery of fear memory, a result that agrees with reports showing no spontaneous recovery of fear memory $1 \mathrm{wk}$ after impairing memory reconsolidation (Duvarci and Nader 2004; Bustos et al. 2006; Stern et al. 2012). The reconsolidation time-window is suggested to last up to $6 \mathrm{~h}$ after reactivation (Nader et al. 2000; Bustos et al. 2006; Stern et al. 2012). Indeed, the TMX infusion into the PL $6 \mathrm{~h}$ after memory reactivation did not change the freezing behavior when the animals underwent Test $\mathrm{A}_{1}$ (24 h later), confirming previous studies showing that at this time-point interferences in memory reconsolidation are not observed (Nader et al. 2000; Stern et al. 2012). However, a reduction in freezing behavior, but not significant, was observed in Test $A_{1}$ of TMX-treated rats. Since only one dose of TMX was tested,

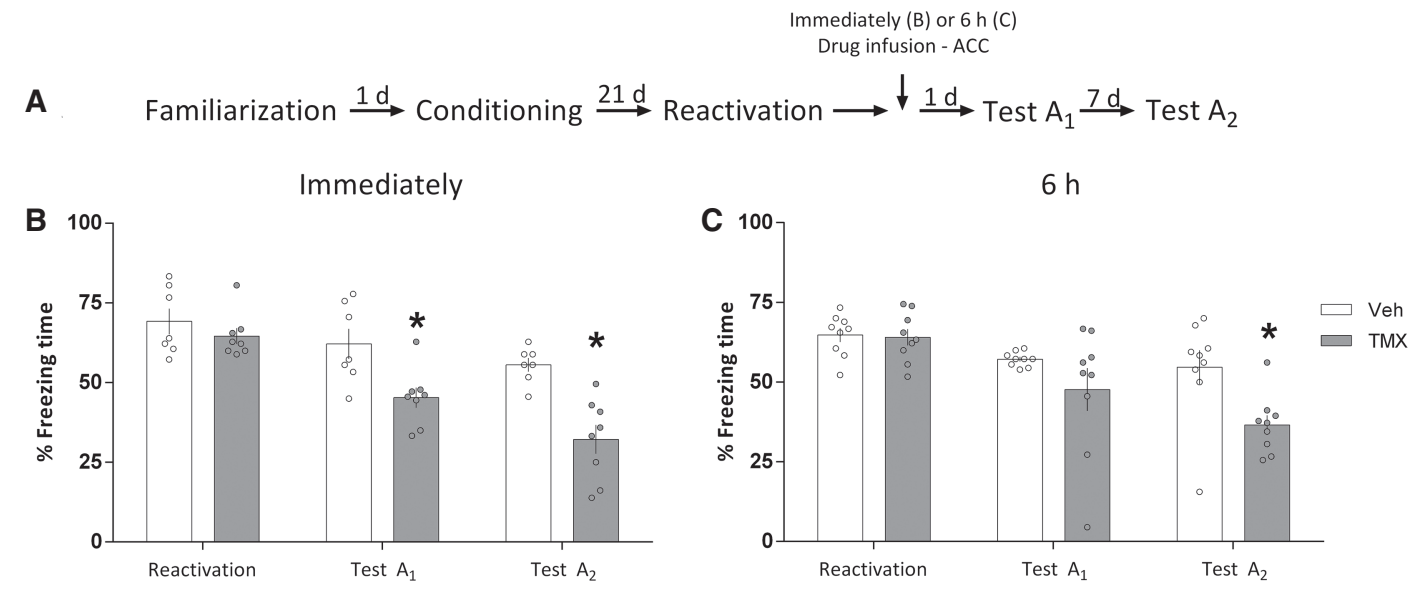

Figure 4. Remote fear memory reconsolidation and persistence relies on the ACC. (A) The diagram represents the experimental design. Animals were familiarized to Context A, that was paired with three footshocks (US) a day later. After $21 \mathrm{~d}$, immediately or $6 \mathrm{~h}$ after remote memory reactivation, the animals received a bilateral infusion of either vehicle (Veh) or TMX $(0.25 \mu \mathrm{g} / 0.2 \mu \mathrm{L})$ intra-ACC. One and seven days later, the animals were submitted to Tests $A_{1}$ and $A_{2}$ to assess TMX effects on memory. (B) Effects of TMX when given into ACC immediately after reactivation of remote fear memory. TMX-treated animals presented less freezing time than controls during Test $A_{1}$ and Test $A_{2}$, suggesting an impairment of remote memory reconsolidation. (C) Effects of TMX when given into ACC $6 \mathrm{~h}$ after reactivation of remote fear memory. TMX-treated animals presented less freezing time than controls only during Test $\mathrm{A}_{2}$, suggesting an impairment of recent memory persistence. Values are expressed as mean \pm S.E.M. The asterisk indicates a statistically significant difference $(P \leq 0.05)$ from the respective control group (Repeated-measures ANOVA followed by the Tukey test). 
it remains to be confirmed whether no short-term amnesic effect is indeed observed $6 \mathrm{~h}$ after memory reactivation. However, when these animals were retested $7 \mathrm{~d}$ later, a reduction in freezing behavior was observed, suggesting an impairing effect in memory persistence. Of note, a similar result was observed after the systemic administration of TMX, the inhibition of PKC or PKM $\zeta$ in the PL cortex, or the inhibition of protein synthesis in the basolateral amygdala (Nakayama et al. 2013; da Silva et al. 2016, 2020). Together, these results provide further evidence that the PL is recruited for recent fear memory reconsolidation and persistence of reactivated fear memory.

Consistent with the reconsolidation theory, it has been observed that the earlier the intervention is performed after memory retrieval, the weaker the memory trace will be reconsolidated (Helfer and Shultz 2019). For instance, MK801 impaired procedural memory reconsolidation when administered up to $90 \mathrm{~min}$ after retrieval and anisomycin caused passive-avoidance amnesia in mice when injected 30 min or less after memory reactivation (Judge and Quartermain 1982; Przybyslawski and Sara 1997). Further, inhibiting mRNA synthesis in the hippocampus immediately, but not $3 \mathrm{~h}$ after spatial memory reactivation, impaired memory reconsolidation (da Silva et al. 2008) and either cannabidiol or delta-9tetrahydrocannabidiol impaired memory reconsolidation immediately or $30 \mathrm{~min}$ after contextual fear memory reactivation, but not $6 \mathrm{~h}$ later (Stern et al. 2012, 2015). Together, these studies suggest that when memory retrieval and the drug administration become unpaired on time, no short-term amnesic effect is observed. However, inhibiting the protein synthesis or Arc expression in basolateral amygdala $9.5 \mathrm{~h}$ or $7 \mathrm{~h}$ after memory retrieval, respectively, induced a long-term amnesic effect, altering the animal behavior 7 d, but not 2 d later (Nakayama et al. 2013, 2016). A similar result was observed here with TMX administration or when the PKM $\zeta$ in the PL cortex was inhibited $6 \mathrm{~h}$ or PKC 6, 9 or $12 \mathrm{~h}$ after memory retrieval (da Silva et al. 2020). Curiously, inhibiting PL cortex PKM $\zeta 1 \mathrm{~h}$, or hippocampal ERK1/2 $3 \mathrm{~h}$, after memory retrieval specifically impaired memory persistence (Krawczyk et al. 2016; da Silva et al. 2020). Thus, suggesting that memory reactivation triggers independent mechanisms underlying memory reconsolidation and/or persistence, however, evidence on these aspects are still incipient.

It has been suggested that the reconsolidation of recent memories is less dependent on cortical regions such as the ACC (Do-Monte et al. 2013; Makino et al. 2019). To explore this, the effect of TMX infused in this region immediately or $6 \mathrm{~h}$ after recent memory reactivation was investigated. The infusion of TMX into the ACC immediately after memory reactivation did not change the freezing behavior when compared to controls 1 or 7 $\mathrm{d}$ later, suggesting no impairment in memory reconsolidation and persistence. This result is in line with works showing that the infusion of anisomycin into the ACC of mice after reactivation of a recent fear memory did not change the freezing behavior (Frankland et al. 2006). However, our result contrasts with findings showing that anisomycin given into the rat ACC immediately after reactivation of a recent fear memory impaired memory reconsolidation (Einarsson and Nader 2012). The intensity of conditioning training or previous stress has been suggested as a boundary condition to memory labilization and reconsolidation (Alberini 2011; Espejo et al. 2016), however, this factor is unlikely to account for the different results observed, since we have adopted a weaker fear conditioning protocol than Einarsson and Nader (2012). Another difference is the drug used, since anisomycin blocks protein synthesis, while TMX interferes with estrogenmediated signaling and inhibits PKC (Horgan et al. 1986; O'Brian et al. 1990). The PKC role in memory reconsolidation has been addressed. For instance, inhibiting PKC in the dorsal hippocampus or the PL cortex immediately after memory retriev- al impaired recent fear memory reconsolidation (Bonini et al. 2007; da Silva et al. 2020). However, the hippocampal contribution to recent memory reconsolidation is greater than that of the cortical areas such as the ACC (Webb et al. 2017). Together, our findings reinforce previous results suggesting that the ACC is not involved in recent fear memory reconsolidation and suggest that this area is not recruited for persistence of reactivated recent fear memories.

Then, to investigate whether the PL cortex and ACC would be recruited for reconsolidation and/or persistence of an older memory, rats received TMX into the PL cortex immediately after reactivation of remote fear memory. A significant and long-lasting reduction in freezing behavior was shown when compared with controls during Test $A_{1}$, suggesting an impairment of remote fear memory reconsolidation. This result is in line with previous studies showing that the activity of the PL cortex underlies reconsolidation of remote fear memory (Stern et al. 2014). Further, this result suggests the participation of estrogen receptors and/or PKC activity in this area underlying remote fear memory reconsolidation. However, to the best of our knowledge, no studies are investigating these aspects. TMX-treatment into the PL cortex $6 \mathrm{~h}$ after the reactivation of a remote fear memory did not change freezing behavior when animals were tested $1 \mathrm{~d}$ later, confirming that after the end of the reconsolidation time-window, no effect is observed on the following day. Further, no reduction in freezing behavior was observed $7 \mathrm{~d}$ later, suggesting that persistence of reactivated remote fear memory is independent of the PL cortex. It has been proposed that recent memory retrieval may trigger mechanisms that independently govern memory reconsolidation and persistence (Krawczyk et al. 2016, 2019; da Silva et al. 2020). Here, we observed that PL cortex subserves the reconsolidation of both, recent and remote fear memory, however, the long-term effect of TMX, observed when it was infused $6 \mathrm{~h}$ after memory reactivation, is spared in remote fear memory, suggesting that the mechanisms underlying remote memory reconsolidation and persistence do not overlap in the PL cortex.

When TMX was given into the ACC immediately after reactivation of the remote fear memory, it produced a significant reduction in freezing behavior when compared with controls during Test $A_{1}$, suggesting an impairment of memory reconsolidation. Importantly, the effect lasted at least $1 \mathrm{wk}$ (Test $\mathrm{A}_{2}$ ), suggesting no spontaneous recovery of the fear memory. This result is in line with previous studies showing that protein synthesis inhibition in this area disrupted remote contextual fear memory reconsolidation (Einarsson and Nader 2012), however, it disagrees with a study showing that protein synthesis inhibition in the ACC immediately after remote memory reactivation is resistant to the reconsolidation-impairing effect (Frankland et al. 2006). This difference might be related to the treatment adopted, since TMX interferes with specific intracellular signaling pathways (Zarate and Manji 2009) and anisomycin disrupts the general protein synthesis; the species used, that is, rats versus mice; and the memory age since Frankland et al. (2006) tested a 36-d old memory and here a 21 -d old fear memory was tested. Together, the present results provide further evidence on the role of the ACC in remote fear memory reconsolidation.

When TMX was infused into ACC $6 \mathrm{~h}$ after remote fear memory reactivation, no effect was observed on the following day, a result consistent with a study showing that the blockade of AMPA/ kainate receptors in the ACC $6 \mathrm{~h}$ after remote memory reactivation did not affect freezing expression $24 \mathrm{~h}$ later (Einarsson et al. 2015). Here, a significant reduction in freezing behavior of TMX-treated rats was observed $7 \mathrm{~d}$ later, suggesting that persistence of reactivated remote fear memory depends on the ACC, providing evidence that memory retrieval may trigger mechanisms underpinning remote fear memory reconsolidation and persistence along the 
medial prefrontal cortex, and that remote memory reconsolidation, but not its persistence, overlap in PL.

It is well accepted that ACC activity sustains the expression of remote memories (Frankland et al. 2004). However, since the effect of TMX $6 \mathrm{~h}$ after reactivation of remote fear memory in the ACC was not tested in the absence of the Test $A_{1}$, we cannot exclude the possibility that TMX effect is a long-term effect in fear memory retrieval, as observed by other authors (Parsons and Davis 2011). The connections between the ACC, dorsal hippocampus and entorhinal cortex are important not only to sustain remote fear memories, but it is also necessary for memory consolidation (Insel and Takehara-Nishiuchi 2013; Tayler et al. 2013; Bero et al. 2014;). For instance, optogenetic inhibition of the medial prefrontal cortex inhibited the entorhinal-hippocampal circuit activation and impaired long-term memory consolidation, suggesting that early cortical activity is critical for a stimulus-induce hippocampal activation and memory consolidation (Bero et al. 2014). At a recent, but not at a remote time point, spine density or c-Fos expression is higher in the hippocampus than in ACC of fear conditioned rats, whereas an inverse temporal pattern is observed in ACC, suggesting that gradual changes occur modifying the connectivity between the hippocampus and the ACC after the formation and reactivation of the remote memory (Restivo et al. 2009; Aceti et al. 2015). These studies align with the hypothesis that enhancement of ACC activity along time supports remote fear memories expression. However, some studies suggest that the CA1 region

\section{A}
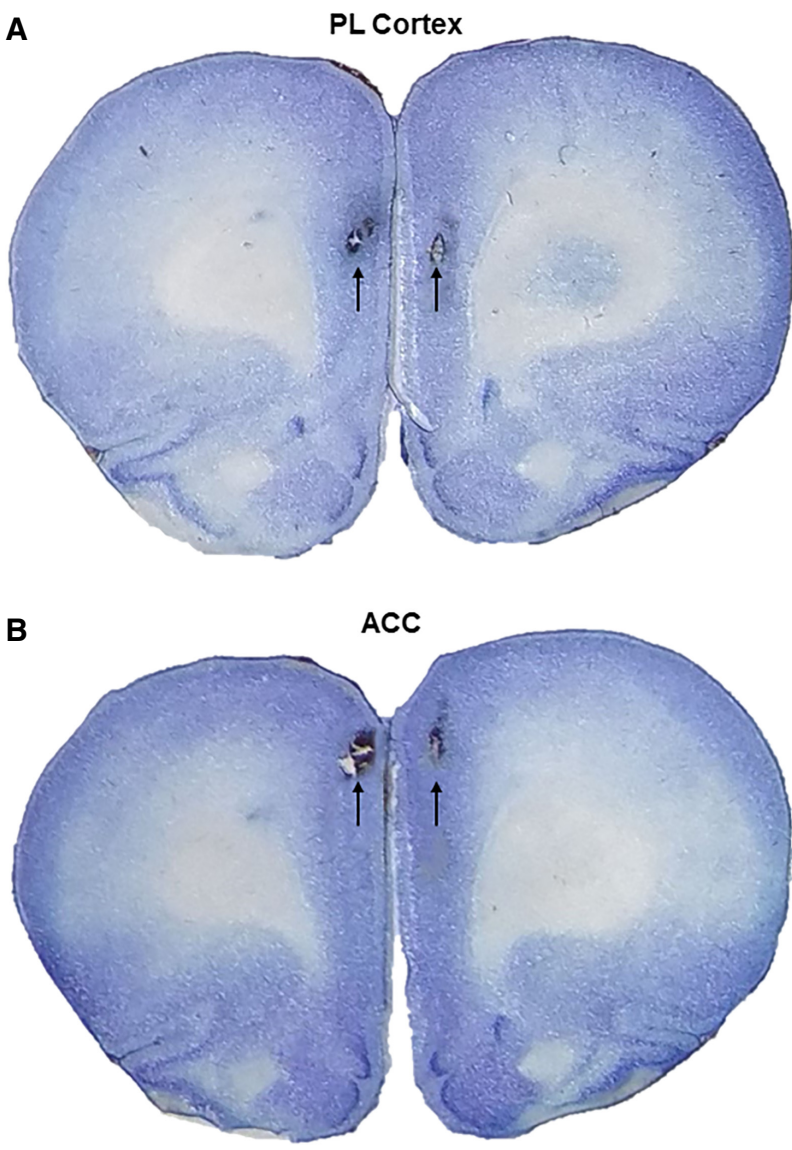

Figure 5. The representative sites of drug infusion in the prelimbic and anterior cingulate cortices. $(A)$ The arrowhead indicates the methylene blue tag in the prelimbic cortex (PL cortex). (B) The arrowhead indicates the methylene blue tag in the anterior cingulate cortex (ACC). of the hippocampus is required for remote memory reactivation since inhibiting the protein synthesis in the hippocampus impaired a remote memory reconsolidation (Debiec et al. 2002; Goshen et al. 2011). It remains to be investigated whether these connections contribute to the TMX effect observed in the persistence of remote memory and to the dissociation of the ACC and the PL cortex participation in the reconsolidation and persistence processes.

The effects of TMX observed here agree with works showing the role of PKC in memory reconsolidation and persistence (Bonini et al. 2007; da Silva et al. 2016, 2020). However, its potential effect as a modulator of estrogen receptors cannot be excluded. The ERalpha and ERbeta estrogen receptors are expressed in the medial prefrontal cortex (Almey et al. 2014), ample evidence supports their role in memory processing (Tuscher et al. 2015) and the TMX consolidation impairing effect of inhibitory avoidance depended on ERalpha receptors (Lichtenfels et al. 2017). Furthermore, studies comparing males and females have suggested differences in fear memory consolidation, extinction, and labilization/reconsolidation processing (Chang et al. 2009; da Silva et al. 2016; Franzen et al. 2019). Given systemically, TMX did not impair fear memory persistence in estrous females, although it similarly impaired memory persistence in proestrous and diestrous females and in males (da Silva et al. 2016). However, it is yet unknown whether and which estrogen receptor located in the medial prefrontal cortex is involved in TMX-induced effects in recent and remote fear memory reconsolidation and persistence.

In conclusion, our findings provide further evidence on the role of the PL and the ACC in recent and remote fear memory reconsolidation and suggest that as memory ages, the persistence of a reactivated fear memory becomes independent of the PL cortex and dependent of the ACC.

\section{Materials and Methods}

\section{Animals}

Adult male Wistar rats, 3 mo old, weighing between 290-320 g (from the Biological Sciences Sector of the Federal University of Paraná) were used. The animals were housed in plastic home cages in groups of four to five per cage with access to food and water ad libitum. The animals were kept in controlled temperatures of $22 \pm$ $2^{\circ} \mathrm{C}$ and a 12-h light-dark cycle (7:00 a.m.-19:00 p.m.). The experiments were performed in accordance with the Guide for the Care and Use of Laboratory Animals and the ARRIVE Guidelines (National Research Council 2011), and after the approval of the experimental protocol by the Ethics Committee for the care and use of laboratory animals of the Biological Sciences Sector of the Federal University of Paraná (authorization number 1011).

\section{Drug}

Tamoxifen (TMX; $0.25 \mu \mathrm{g} / 0.2 \mu \mathrm{L}$ Sigma) a nonselective PKC inhibitor and a selective estrogen response modifier, was dissolved in saline containing $20 \%$ dimethyl sulfoxide, that alone was used as control (DMSO; Talebi et al. 2010).

\section{Stereotaxic surgery and drug infusion}

Rats were acclimated in the laboratory vivarium for $24 \mathrm{~h}$ and then were anesthetized with ketamine (75 mg/kg; Carlier, Brazil) and xylazine (15 mg/kg; Sespo, Brazil), associated with local anesthesia (3.0\% lidocaine with norepinephrine 1:50000; Dentsply, Brazil). After anesthesia, rats were positioned in a stereotaxic frame and two stainless-steel guide cannulas (length: $11 \mathrm{~mm}$; outer diameter: $0.7 \mathrm{~mm}$ ) were implanted bilaterally aiming at the PL cortex or ACC following the coordinates $(\mathrm{AP}=+11.8 \mathrm{~mm}$ interaural, $\mathrm{ML}= \pm 0.6$ from central suture, $\mathrm{DV}=-1.8$ from the skull) of The Rat Brain in Stereotaxic Coordinates (Paxinos and Watson 2009) and with two screws and dental acrylic they were fixed to the skull. A stylet 
was introduced inside each guide cannula to prevent obstruction. After the surgery, the animals received $0.4 \mathrm{~mL}$ of ibuprofen orally (20 mg/mL, Natulab, Brazil), and returned to the home cage.

After $10 \mathrm{~d}$, the animals underwent the protocol of contextual fear conditioning. Immediately or $6 \mathrm{~h}$ after memory reactivation, rats received a bilateral infusion with dental needles introduced through the guide cannulas until their tips were $1.5 \mathrm{~mm}$ (PL cortex) or $1.2 \mathrm{~mm}$ (ACC) below the cannula end.

The drug was injected over $1 \mathrm{~min}(0.2 \mu \mathrm{L} /$ side $)$ using two 5.0 $\mu \mathrm{L}$ Hamilton syringes connected to an automatic infusion pump (Insight, Brazil). A polyethylene catheter was inserted between the upper end of the dental needles and the syringes. To monitor the flow of the drug, an air bubble was displaced inside the polyethylene. The needles were kept for additional a $45 \mathrm{sec}$ after the end of the injections to prevent backflow.

After the end of experiments, the animals were anesthetized as mentioned above, the methylene blue was infused through the guide cannulas, the animals were killed, and the brains were removed to confirm the drug infusion sites. Brain slices (50 $\mu \mathrm{m}$ thick) were obtained on a vibratome (Leica), and slides were mounted, stained with nissl, and the infusion site was ascertained. The animals were included in the statistical analysis when the infusion was bilateral in the PL or ACC cortices (Fig. 5).

\section{General procedures}

To avoid possible circadian influences on learning and memory processing, the experiments were performed between 1:00 and 5:00 P.M. and conducted similarly to previous studies (da Silva et al. 2020). All animals were moved and acclimated to the experimental room for $30 \mathrm{~min}$ before each session. The experimental rooms were kept under controlled temperature $\left(21 \pm 2^{\circ} \mathrm{C}\right)$ and brightness ( $\sim 8$ lux).

Contextual fear conditioning was done in Context A, a chamber, made of gray aluminum sidewalls, with a transparent acrylic top cover and front wall $(26 \times 31.5 \times 21 \mathrm{~cm}$; Insight, Brazil $)$, the floor was composed of stainless steel-bars $(3 \mathrm{~mm}$ in diameter and spaced $0.9 \mathrm{~mm}$ ) connected to a shock generating source. Context B $(34 \times 26 \times 33 \mathrm{~cm})$, an unpaired chamber, had transparent acrylic walls and floor, and a black top cover to provide different clues from the paired context. Context B was used to assess the generalization of fear.

Contextual fear conditioning protocol consisted of the following sessions: on the first day the animals were familiarized to Context A for $3 \mathrm{~min}$. After $24 \mathrm{~h}$, the animals were submitted to Context A, after the initial 30 sec the animals received the unconditioned stimulus (US) that consisted of three footshocks of 0.8 $\mathrm{mA} / 3 \mathrm{sec}$ in $30 \mathrm{sec}$ intervals. After the last US, the animal remained for $30 \mathrm{sec}$ in Context A and then returned to the home cage. When the recent memory was evaluated, the reactivation session was conducted $24 \mathrm{~h}$ after conditioning and the animals were exposed to Context A for 3 min without the US presentation. After this session, the animals received immediately or $6 \mathrm{~h}$ later, bilateral infusions of vehicle or TMX into the PL cortex or ACC. After 1 or $7 \mathrm{~d}$, the animals were reexposed to Context $\mathrm{A}$ for $3 \mathrm{~min}$, these sessions were named Test $A_{1}$ and Test $A_{2}$, respectively. To evaluate the remote memory, the animals were submitted to a reactivation session $21 \mathrm{~d}$ after fear conditioning (Stern et al. 2014). Then, the animals received immediately or after $6 \mathrm{~h}$, bilateral infusions of vehicle or TMX into the PL cortex or ACC. One or $7 \mathrm{~d}$ later, the animals were submitted to Test $A_{1}$, and Test $A_{2}$, respectively. The chambers were cleaned with a $10 \%$ ethanol/water solution after each session.

The freezing behavior, characterized as the total absence of body and head movements, except those associated with breathing (Blanchard and Blanchard 1969) was evaluated. The sessions were recorded by a video camera and freezing time was quantified in seconds using a stopwatch by a blind and trained observer and expressed as a percentage of the total session time.

After the end of the behavioral experiments, to confirm the injection side, the rats were anesthetized using $1.0 \mathrm{~mL} / \mathrm{kg}$ of a solution containing xylazine $(10 \mathrm{mg} / \mathrm{mL}$, Carlier) and chloral hydrate (2.3 mg/mL, Vetec) intraperitoneally (i.p.). Methylene Blue dye
(0.2 $\mu \mathrm{L} /$ hemisphere) was injected through the guide cannulas for the subsequent evaluation of the locations where vehicle or TMX was infused.

Brains were removed and immersed in a $10 \%$ formalin solution. The brain slices (50 $\mu \mathrm{m}$ thick) were obtained in a vibratome (Leica), mounted on microscope glass slides, and the injection site was determined. Animals were included in the analysis when both sides of the PL cortex or the ACC were correctly marked by methylene blue.

\section{Experimental design}

Experiment 1: To evaluate whether TMX infused into the PL cortex interferes in the reconsolidation or persistence of a reactivated recent memory rats that underwent contextual fear conditioning were randomly allocated to receive a bilateral infusion of either vehicle or TMX $(0.25 \mu \mathrm{g} / 0.2 \mu \mathrm{L} /$ side $)$ intra-PL cortex immediately or $6 \mathrm{~h}$ after the reactivation session (Fig. 1).

Experiment 2: To evaluate whether TMX infused into the ACC interferes in the reconsolidation or persistence of a reactivated recent memory rats that underwent contextual fear conditioning were randomly allocated to receive a bilateral infusion of either vehicle or TMX $(0.25 \mu \mathrm{g} / 0.2 \mu \mathrm{L} /$ side $)$ intra-ACC immediately or $6 \mathrm{~h}$ after the reactivation session (Fig. 2).

Experiment 3: To evaluate whether TMX infused into the PL cortex interferes in the reconsolidation or persistence of a reactivated remote memory, rats that underwent contextual fear conditioning were randomly allocated to receive a bilateral infusion of either vehicle or TMX $(0.25 \mu \mathrm{g} / 0.2 \mu \mathrm{L} /$ side $)$ intra-PL cortex immediately or $6 \mathrm{~h}$ after the reactivation session (Fig. 3).

Experiment 4: To evaluate whether TMX infused into the ACC interferes in the reconsolidation or persistence of a reactivated remote memory, rats that underwent contextual fear conditioning were randomly allocated to receive a bilateral infusion of either vehicle or TMX $(0.25 \mu \mathrm{g} / 0.2 \mu \mathrm{L} /$ side $)$ intra-ACC immediately or $6 \mathrm{~h}$ after the reactivation session (Fig. 4).

\section{Statistical analysis}

The results are expressed as mean \pm S.E.M. After ensuring the homogeneity of the data, the percentage of freezing time observed in Context $A$ (reactivation session, Test $A_{1}$, and Test $A_{2}$ ) was analyzed by repeated-measures analysis of variance (ANOVA). The Tukey test was used for post-hoc comparisons when ANOVA achieved significant interaction between the main factors treatment and reexposures to Context A. The level of statistical significance was set at $P \leq 0.05$. For statistical analysis, Statistica 12 (StatSoft) was used, and GraphPad Prism 8 (GraphPad Prism) was used for graphing. The formula for Hedges' $g$, which reflect the mean differences between two groups ( $n \leq 20$ per group) that could be dissimilar in size, was used to calculate the size effect. Large effect size was considered when the g value was $\geq 0.8$ (Ellis 2010).

\section{Competing interests statement}

The authors declare no competing interests.

\section{Acknowledgments}

Our study was supported by Brazilian grants from Fundação Araucária (39.651/2014) and by the Coordenação de Aperfeiçoamento de Pessoal de Nível Superior-Brasil (CAPES)-Finance Code 001. Fundação Araucária and CAPES had no further role in study design; in the collection, analysis, and interpretation of data; in the writing of the report; and in the decision to submit the paper for publication.

Authors contributions: T.R.S.: conducted the experiments, C.A. S, R.A., J.M.B.S., and T.R.S.: data analysis and interpretation, C.A.S, R.A., J.M.B.S., and T.R.S.: elaborated the work design, interpreted the results, and wrote the paper. 


\section{References}

Abrial E, Etievant A, Bétry C, Scarna H, Lucas G, Haddjeri N, Lambás-Señas L. 2013. Protein kinase $C$ regulates mood-related behaviors and adult hippocampal cell proliferation in rats. Prog Neuro Psychopharmacol Biol Psychiatry 43: 40-48. doi:10.1016/j.pnpbp.2012.11.015

Aceti M, Vetere G, Novembre G, Restivo L, Ammassari-Teule M. 2015. Progression of activity and structural changes in the anterior cingulate cortex during remote memory formation. Neurobiol Learn Mem 123: 6771. doi:10.1016/j.nlm.2015.05.003

Alberini CM. 2011. The role of reconsolidation and the dynamic process of long-term memory formation and storage. Front Behav Neurosci 5: 12. doi:10.3389/fnbeh.2011.00012

Almey A, Cannell E, Bertram K, Filardo E, Milner TA, Brake WG. 2014. Medial prefrontal cortical estradiol rapidly alters memory system bias in female rats: ultrastructural analysis reveals membrane-associated estrogen receptors as potential mediators. Endocrinology 155: 44224432. doi:10.1210/en.2014-1463

Amiri S, Jafarian Z, Vafaei AA, Motaghed-Larijani Z, Samaei SA, Rashidy-Pour A. 2015. Glucocorticoids interact with cholinergic system in impairing memory reconsolidation of an inhibitory avoidance task in mice. Basic Clin Neurosci 6: 155-162.

Bero AW, Meng J, Cho S, Shen AH, Canter RG, Ericsson M, Tsai LH. 2014. Early remodeling of the neocortex upon episodic memory encoding. Proc Natl Acad Sci 111: 11852-11857. doi:10.1073/pnas.1408378111

Blanchard RJ, Blanchard DC. 1969. Passive and active reactions to fear-eliciting stimuli. J Comp Physiol Psychol 68: 129-135. doi:10.1037/ h0027676

Bonini JS, Da Silva WC, Bevilaqua LRM, Medina JH, Izquierdo I, Cammarota M. 2007. On the participation of hippocampal PKC in acquisition, consolidation and reconsolidation of spatial memory. Neuroscience 147: 37-45. doi:10.1016/j.neuroscience.2007.04.013

Bustos SG, Maldonado H, Molina VA. 2006. Midazolam disrupts fear memory reconsolidation. Neuroscience 139: 831-842. doi:10.1016/j .neuroscience.2005.12.064

Chang YJ, Yang CH, Liang YC, Yeh CM, Huang CC, Hsu KS. 2009. Estrogen modulates sexually dimorphic contextual fear extinction in rats through estrogen receptor $\beta$. Hippocampus 19: 1142-1150. doi:10.1002/hipo .20581

da Silva WC, Bonini JS, Bevilaqua LRM, Medina JH, Izquierdo I, Cammarota M. 2008. Inhibition of mRNA synthesis in the hippocampus impairs consolidation and reconsolidation of spatial memory. Hippocampus 18: 29-39. doi:10.1002/hipo.20362

da Silva TR, Takahashi RN, Bertoglio LJ, Andreatini R, Stern CAJ. 2016. Evidence for an expanded time-window to mitigate a reactivated fear memory by tamoxifen. Eur Neuropsychopharmacol 26: 1601-1609. doi:10.1016/j.euroneuro.2016.08.005

da Silva TR, Raymundi AM, Bertoglio LJ, Andreatini R, Stern CAJ. 2020. Role of prelimbic cortex PKC and PKM $\zeta$ in fear memory reconsolidation and persistence following reactivation. Sci Rep 10: 4076. doi:10.1038/ s41598-020-60046-X

Debiec J, LeDoux JE, Nader K. 2002. Cellular and systems reconsolidation in the hippocampus. Neuron 36: 527-538. doi:10.1016/S0896-6273(02) 01001-2

DeNardo LA, Liu CD, Allen WE, Adams EL, Friedmann D, Fu L, Guenthner CJ, Tessier-Lavigne M, Luo L. 2019. Temporal evolution of cortical ensembles promoting remote memory retrieval. Nat Neurosci 22: 460-469. doi:10.1038/s41593-018-0318-7

Dolleman-van der Weel MJ, Griffin AL, Ito HT, Shapiro ML, Witter MP, Vertes RP, Allen TA. 2019. The nucleus reuniens of the thalamus sits at the nexus of a hippocampus and medial prefrontal cortex circuit enabling memory and behavior. Learn Mem 26: 191-205. doi:10.1101/ $\operatorname{lm} .048389 .118$

Do Monte FH, Souza RR, Wong TT, de Carobrez AP. 2013. Systemic or intra-prelimbic cortex infusion of prazosin impairs fear memory reconsolidation. Behav Brain Res 244: 137-141. doi:10.1016/j.bbr.2013 .01 .031

Duvarci S, Nader K. 2004. Characterization of fear memory reconsolidation. J Neurosci 24: 9269-9275. doi:10.1523/JNEUROSCI.2971-04.2004

Eigeliene N, Erkkola R, Härkönen P. 2016. Comparison of the effects of the selective estrogen receptor modulators ospemifene, raloxifene, and tamoxifen on breast tissue in ex vivo culture. In Methods in molecular biology, Vol. 1366, pp. 327-336. Humana Press Inc.

Einarsson EO, Nader K. 2012. Involvement of the anterior cingulate cortex in formation, consolidation, and reconsolidation of recent and remote contextual fear memory. Learn Mem 19: 449-452. doi:10.1101/lm .027227 .112

Einarsson EÖ, Pors J, Nader K. 2015. Systems reconsolidation reveals a selective role for the anterior cingulate cortex in generalized contextual fear memory expression. Neuropsychopharmacology 40: 480-487. doi:10 $.1038 /$ npp.2014.197
Ellis PD. 2010. The essential guide to effect sizes: statistical power, meta-analysis, and the interpretation of research results. Cambridge University Press.

Espejo PJ, Ortiz V, Martijena ID, Molina VA. 2016. Stress-induced resistance to the fear memory labilization/reconsolidation process. Involvement of the basolateral amygdala complex. Neuropharmacology 109: 349-356. doi:10.1016/j.neuropharm.2016.06.033

Frankland P, Bontempi B, Talton LE, Kaczmareck L, Silva AJ. 2004. The involvement of the anterior cingulate cortex in remote contextual fear memory. Science 204: 881-883.

Frankland PW, Ding HK, Takahashi E, Suzuki A, Kida S, Silva AJ. 2006. Stability of recent and remote contextual fear memory. Learn Mem 13: 451-457. doi:10.1101/lm.183406

Franzen JM, Giachero M, Bertoglio LJ. 2019. Dissociating retrieval-dependent contextual aversive memory processes in female rats: are there cycle-dependent differences? Neuroscience 406: 542-553. doi:10.1016/j.neuroscience.2019.03.035

Giese KP, Mizuno K. 2013. The roles of protein kinases in learning and memory. Learn Mem 20: 540-552. doi:10.1101/lm.028449.112

Gisquet-Verrier P, Le Dorze C. 2019. Post traumatic stress disorder and substance use disorder as two pathologies affecting memory reactivation: implications for new therapeutic approaches. Front Behav Neurosci 13: 26. doi:10.3389/fnbeh.2019.00026

Goshen I, Brodsky M, Prakash R, Wallace J, Gradinaru V, Ramakrishnan C, Deisseroth K. 2011. Dynamics of retrieval strategies for remote memories. Cell 147: 678-689. doi:10.1016/j.cell.2011.09.033

Helfer P, Shultz TR. 2019. A computational model of systems memory consolidation and reconsolidation. Hippocampus doi:10.1002/hipo .23187

Horgan K, Cooke E, Hallett MB, Mansel RE. 1986. Inhibition of protein kinase $\mathrm{C}$ mediated signal transduction by tamoxifen. Importance for antitumour activity. Biochem Pharmacol 35: 4463-4465. doi:10.1016/ 0006-2952(86)90764-1

Inaba N, Takemura A, Kawano K. 2016. Representing spatial information in the parietal association cortex authors. Brain Nerve 68: 1321-1333.

Insel N, Takehara-Nishiuchi K. 2013. The cortical structure of consolidated memory: a hypothesis on the role of the cingulate-entorhinal cortical connection. Neurobiol Learn Mem 106: 343-350. doi:10.1016/j.nlm 2013.07.019

Judge ME, Quartermain D. 1982. Characteristics of retrograde amnesia following reactivation of memory in mice. Physiol Behav 28: 585-590. doi:10.1016/0031-9384(82)90034-8

Krawczyk MC, Navarro N, Blake MG, Romano A, Feld M, Boccia MM. 2016. Reconsolidation-induced memory persistence: participation of late phase hippocampal ERK activation. Neurobiol Learn Mem 133: 79-88. doi:10.1016/j.nlm.2016.06.013

Krawczyk MC, Millan J, Blake MG, Feld M, Boccia MM. 2019. Relevance of ERK1/2 post-retrieval participation on memory processes: insights in their particular role on reconsolidation and persistence of memories. Front Mol Neurosci 12: 95. doi:10.3389/fnmol.2019.00095

Lee JLC. 2010. Memory reconsolidation mediates the updating of hippocampal memory content. Front Behav Neurosci 4: 168.

Levin N, Kritman M, Maroun M, Akirav I. 2017. Differential roles of the infralimbic and prelimbic areas of the prefrontal cortex in reconsolidation of a traumatic memory. Eur Neuropsychopharmacol 27: 900-912. doi:10.1016/j.euroneuro.2017.06.007

Lichtenfels M, da Dornelles AS, Petry FDS, Blank M, de Farias CB, Roesler R, Schwartsmann G. 2017. The anticancer estrogen receptor antagonist tamoxifen impairs consolidation of inhibitory avoidance memory through estrogen receptor $\alpha$. J Neural Transm 124: 1331-1339. doi:10 .1007/s00702-017-1785-9

Lisboa SF, Vila-Verde C, Rosa J, Uliana DL, Stern CAJ, Bertoglio LJ, Resstel LB, Guimaraes FS. 2019. Tempering aversive/traumatic memories with cannabinoids: a review of evidence from animal and human studies. Psychopharmacology (Berl) 236: 201-226. doi:10.1007/ s00213-018-5127-X

Makino Y, Polygalov D, Bolaños F, Benucci A, McHugh TJ. 2019. Physiological Signature of Memory Age in the Prefrontal-Hippocampal Circuit. Cell Rep 29: 3835-3846.e5. doi:10.1016/j.celrep.2019.11.075

Murkar A, Kent P, Cayer C, James J, Durst T, Merali Z. 2019. Cannabidiol and the remainder of the plant extract modulate the effects of $\Delta$ 9-tetrahydrocannabinol on fear memory reconsolidation. Front Behav Neurosci 13: 174 . doi:10.3389/fnbeh.2019.00174

Nader K, Einarsson EÖ. 2010. Memory reconsolidation: an update. Ann N Y Acad Sci 1191: 27-41. doi:10.1111/j.1749-6632.2010.05443.x

Nader K, Schafe GE, Le Doux JE. 2000. Fear memories require protein synthesis in the amygdala for reconsolidation after retrieval. Nature 406: 722-726. doi:10.1038/35021052

Nakayama D, Yamasaki Y, Matsuki N, Nomura H. 2013. Post-retrieval late process contributes to persistence of reactivated fear memory. Learn Mem 6: 307-310. doi:10.1101/lm.029660.112

Nakayama D, Iwata H, Teshirogi C, Ikegaya Y, Matsuki N, Nomura H. 2015. Long-delayed expression of the immediate early gene Arc/Arg3.1 refines 
neuronal circuits to perpetuate fear memory. J Neurosci 35: 819-830. doi:10.1523/JNEUROSCI.2525-14.2015

Nakayama D, Hashikawa-yamasaki Y, Ikegaya Y, Matsuki N. 2016. Late Arc/ Arg3.1 expression in the basolateral amygdala is essential for persistence of newly-acquired and reactivated contextual fear memories. Sci Rep 6: 21007. doi:10.1038/srep21007

National Research Council. 2011. Guide for the care and use of laboratory animals. National Academies Press.

O'Brian CA, Ioannides CG, Ward NE, Liskamp RM. 1990. Inhibition of protein kinase $\mathrm{C}$ and calmodulin by the geometric isomers cis- and trans-tamoxifen. Biopolymers 29: 97-104. doi:10.1002/bip.360290114

Parsons RG, Davis M. 2011. Temporary disruption of fear-potentiated startle following PKMל. Nat Neurosci 14: 295-296. doi:10.1038/nn.2745

Paxinos G, Watson C. 2009. The rat brain in stereotaxic coordinates, 6th ed. Academic, New York.

Przybyslawski J, Sara SJ. 1997. Reconsolidation of memory after its reactivation. Behav Brain Res 84: 241-246. doi:10.1016/S0166-4328(96) 00153-2

Restivo L, Vetere G, Bontempi B, Ammassari-Teule M. 2009. The formation of recent and remote memory is associated with time-dependent formation of dendritic spines in the hippocampus and anterior cingulate cortex. J Neurosci 29: 8206-8214. doi:10.1523/JNEUROSCI .0966-09.2009

Sara SJ. 2010. Reactivation, retrieval, replay and reconsolidation in and out of sleep: connecting the dots. Front Behav Neurosci 4: 185. doi:10.3389/ fnbeh.2010.00185

Stern CAJ, Gazarini L, Takahashi RN, Guimarães FS, Bertoglio LJ. 2012. On disruption of fear memory by reconsolidation blockade: evidence from cannabidiol treatment. Neuropsychopharmacology 37: 2132-2142. doi:10 $.1038 /$ npp.2012.63

Stern CAJ, Gazarini L, Vanvossen AC, Hames MS, Bertoglio LJ. 2014. Activity in prelimbic cortex subserves fear memory reconsolidation over time. Learn Mem 21: 14-20. doi:10.1101/lm.032631.113

Stern CAJ, Gazarini L, Vanvossen AC, Zuardi AW, Galve-Roperh I, Guimaraes FS, Takahashi RN, Bertoglio LJ. 2015. 89-Tetrahydrocannabinol alone and combined with cannabidiol mitigate fear memory through reconsolidation disruption. Eur Neuropsychopharmacol 25: 958-965. doi:10.1016/j.euroneuro.2015.02 .001
Talebi A, Naghdi N, Sepehri H, Rezayof A. 2010. The role of estrogen receptors on spatial learning and memory in CA1 region of adult male rat hippocampus. Iran J Pharm Res IJPR 9: 183-191.

Tayler KK, Tanaka KZ, Reijmers LG, Wiltgen BJ. 2013. Reactivation of neural ensembles during the retrieval of recent and remote memory. Curr Biol 23: $99-106$. doi:10.1016/j.cub.2012.11.019

Tuscher JJ, Fortress AM, Kim J, Frick KM. 2015. Regulation of object recognition and object placement by ovarian sex steroid hormones. Behav Brain Res 285: 140-157. doi:10.1016/j.bbr.2014.08.001

Vanvossen AC, Portes MAM, Scoz-Silva R, Reichmann HB, Stern CAJ, Bertoglio LJ. 2017. Newly acquired and reactivated contextual fear memories are more intense and prone to generalize after activation of prelimbic cortex NMDA receptors. Neurobiol Learn Mem 137: 154-162. doi:10.1016/j.nlm.2016.12.002

Vertes RP. 2006. Interactions among the medial prefrontal cortex, hippocampus and midline thalamus in emotional and cognitive processing in the rat. Neuroscience 142: 1-20. doi:10.1016/j .neuroscience.2006.06.027

Wan X, Torregrossa MM, Sanchez H, Nairn AC, Taylor JR. 2014. Activation of exchange protein activated by cAMP in the rat basolateral amygdala impairs reconsolidation of a memory associated with self-administered cocaine. PLOS ONE 9: e107359. doi:10.1371/journal.pone.0107359

Wang Z, Kyo S, Maida Y, Takakura M, Tanaka M, Yatabe N, Inoue M. 2002. Tamoxifen regulates human telomerase reverse transcriptase (hTERT) gene expression differently in breast and endometrial cancer cells. Oncogene 21: 3517-3524. doi:10.1038/sj.onc.1205463

Webb WM, Sanchez RG, Perez G, Butler AA, Hauser RM, Rich MC, O'Bierne AL, Jarome TJ, Lubin FD. 2017. Dynamic association of epigenetic H3K4me3 and DNA 5hmC marks in the dorsal hippocampus and anterior cingulate cortex following reactivation of a fear memory. Neurobiol Learn Mem 142: 66-78. doi:10.1016/j.nlm.2017.02.010

Ye X, Kapeller-Libermann D, Travaglia A, Inda MC, Alberini CM. 2017. Direct dorsal hippocampal-prelimbic cortex connections strengthen fear memories. Nat Neurosci 20: 52-61. doi:10.1038/nn.4443

Zarate CA, Manji HK. 2009. Protein kinase C inhibitors: rationale for use and potential in the treatment of bipolar disorder. CNS Drugs 23: 569-582. doi:10.2165/00023210-200923070-00003

Received March 6, 2020; accepted in revised form June 1, 2020. 


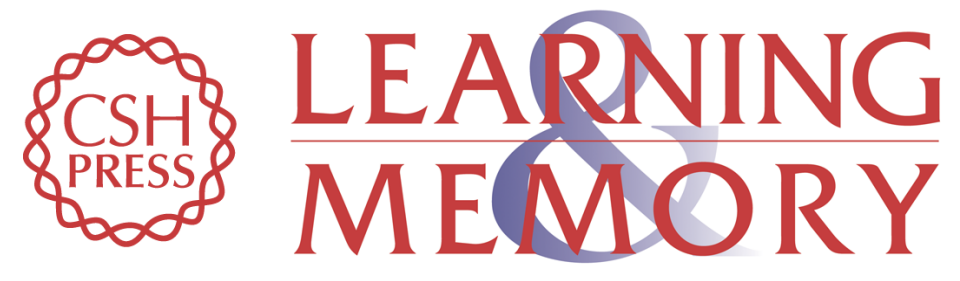

\section{The role of prelimbic and anterior cingulate cortices in fear memory reconsolidation and persistence depends on the memory age}

Thiago Rodrigues da Silva, Jeferson Machado Batista Sohn, Roberto Andreatini, et al.

Learn. Mem. 2020, 27:

Access the most recent version at doi:10.1101/Im.051615.120

References This article cites 64 articles, 9 of which can be accessed free at:

http://learnmem.cshlp.org/content/27/8/292.full.html\#ref-list-1

Creative This article is distributed exclusively by Cold Spring Harbor Laboratory Press for the

Commons

first 12 months after the full-issue publication date (see

License

http://learnmem.cshlp.org/site/misc/terms.xhtml). After 12 months, it is available under a Creative Commons License (Attribution-NonCommercial 4.0 International), as described at http://creativecommons.org/licenses/by-nc/4.0/.

Email Alerting Receive free email alerts when new articles cite this article - sign up in the box at the Service top right corner of the article or click here. 